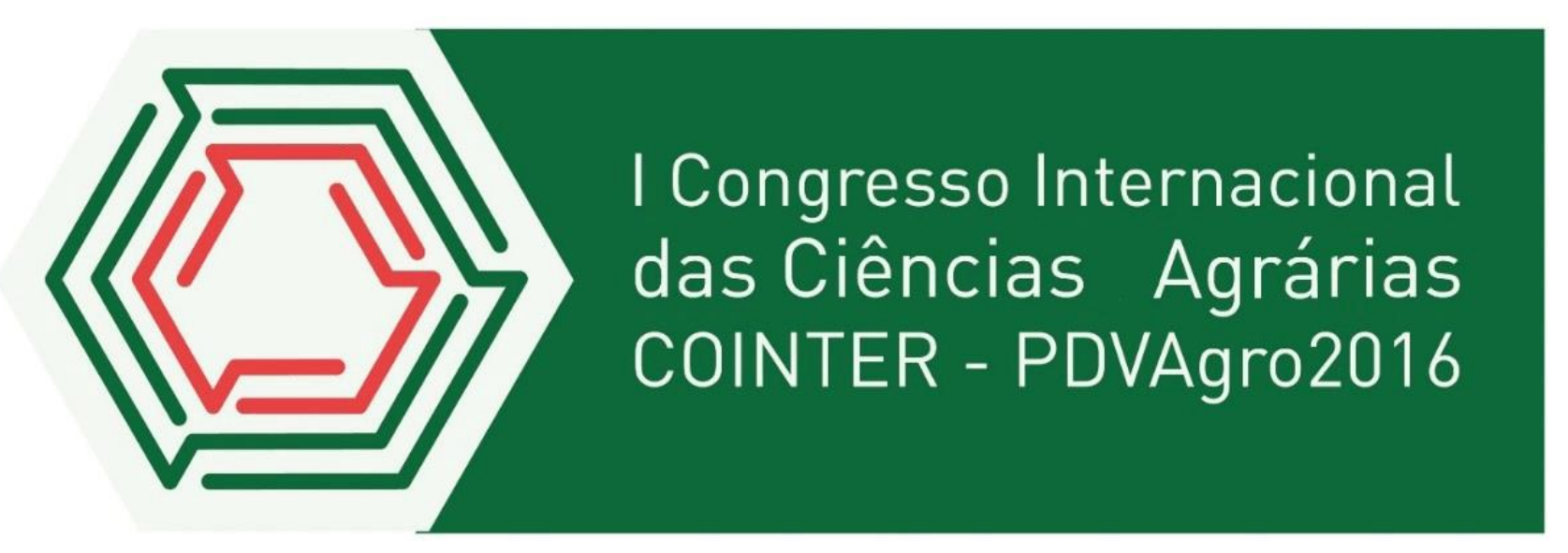

\title{
PRÁTICAS EXTENSIONISTAS EM GRUPO DE TRABALHO: MANEJO INTEGRADO DE PRAGAS (MIP)
}

\author{
Apresentação: Relato de Experiência \\ Timóteo Angelo Nascimento ${ }^{1}$; Erick Viana da Silva ${ }^{2}$
}

\section{Introdução}

O manejo integrado de pragas (MIP) surge em meio a uma lógica de produção agrícola baseada no uso excessivo de produtos químicos para assegurar que insetos não interfiram na produtividade de sua cultura, a chamada lógica convencional (TORRES, 2006). Integrando técnicas, o MIP possibilita ao produtor rural uma maior autonomia na hora da tomada de decisão de acordo com os níveis de dano que o inseto esteja causando em sua produção, apesar de que o MIP tem um enfoque também na prevenção para que não seja caracterizada praga.

\section{Relato de Experiência}

Devido à relevância do assunto, a criação do Grupo de trabalho (GT) com o enfoque no MIP foi validada de acordo com a aceitação de produtores em uma experiência passada no município de Chã Grande - PE, onde em algumas localidades tivemos contatos com agricultores e posteriormente realizamos cursos de formação. Com essa vivência, ao ingressar no Programa Despertando Vocações para Ciências Agrárias (PDVAGRO) vislumbrei a oportunidade de coordenar um GT que demostrasse esse pacote não só aos agricultores das proximidades do Instituto mas também ao público interno do próprio Campus.

Desde que assumimos o compromisso nos deparamos com pontos que nos surpreenderam quanto

\footnotetext{
${ }^{1}$ Bacharelado em Agronomia, Instituto Federal de Educação, Ciência e Tecnologia de Pernambuco, timoteo.ifpe@gmail.com;

${ }^{2}$ Mestre em Administração de Empresas pela Universidade Federal de Alagoas, Instituto Federal de Educação, Ciência e Tecnologia de Pernambuco, Erick.viana@ifpe.edu.br.
} 
extensionistas. Um deles foi à dinâmica completamente diferente do que vimos em Chã Grande em relação ao comportamento da comunidade. No Oiteiro (Zona Rural de Vitória de Santo Antão) estamos nos adaptando aos horários dos produtores, que em sua maioria só nos pode receber-nos no período da noite por em outros horários estarem exercendo sua função profissional ou então dando sequência a sua vida escolar. Já tivemos o primeiro contato com as lideranças da comunidade do Oiteiro e Mocotó e foi realizado um Mini-curso para o público interno.

\section{Imagem 1: Atividade em campo com público interno (21/07/2016). Fonte: Própria}

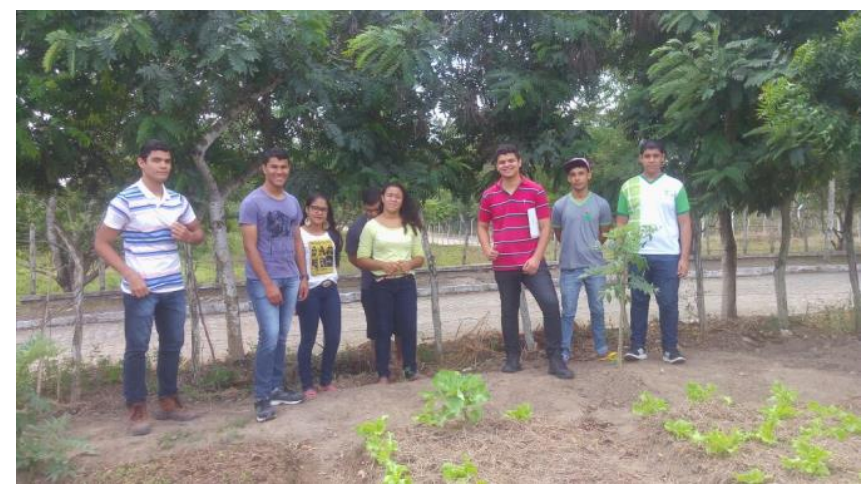

\section{Considerações}

É necessária a continuidade das ações dessa GT para que possa alcançar um publico ainda maior. Vencendo problemas logísticos da Instituição esperamos que o cronograma seja cumprido de forma que atenda o maior número de Agricultores possíveis, e é interessante também a interação de outros GTS do PDVAGRO para que a sistematização possa viabilizar ainda o sucesso de uma produção e conta com o homem e mulher do campo. Os próximos minicursos já estão agendados nas comunidades.

\section{Referências}

. $\quad$ TORRES, J. BRAS. Manejo de Pragas das Plantas Cultivadas - Ênfase Nordeste, Recife. UFRPE. 2006. 